\title{
Four Ports Multiple Input Multiple Output Diversity Antenna for UWB Applications
}

\author{
Vishal T. Repe \\ P. G. Dept., MBES College of Engineering, \\ Ambajogai, India, 431517
}

\author{
Veeresh G. Kasabegoudar \\ P. G. Dept., MBES College of Engineering, \\ Ambajogai, India, 431517
}

\begin{abstract}
A compact MIMO antenna of $52 \times 40 \mathrm{~mm}^{2}$ is presented. It consists of four planar monopole (PM) antenna elements fed with $50-\Omega$ microstrip-line designed on FR4 epoxy substrate. All planar monopole (PM) antennas are square shaped out of which PM1 \& PM2 and, PM3\& PM4 pairs are perpendicular to each other. Ground portion consists of rectangular slot for better impedance matching and four stubs are present to increase isolation and gain. The geometry was optimized to operate in the $3 \mathrm{GHz}$ to $12 \mathrm{GHz}$. The proposed antenna was validated through experimental results and found reasonable agreement between the measured and simulated data
\end{abstract}

\section{Keywords}

Planar monopole (PM), Multiple input multiple output (MIMO), Microstrip antennas.

\section{INTRODUCTION}

Ultra-wideband (UWB) technology for communications and radar has been a topic of research since the early 1960s. However, research and development in this area gained momentum only in recent years for several reasons. Another reason is that these systems were ratified for the first time only in 2002 for unlicensed use under the Federal Communications Commission Part 15 (Title 47 of the Code of Federal Regulations) [FCC. 2002]. The use of UWB in the range of 3.1 to $10.6 \mathrm{GHz}$ was unlicensed by FCC [1]

In wireless communication the amount of diversity can be increased by multiple antennas. For a given multiple antenna channel, both types of gains can be obtained [2]. Another MIMO antenna is proposed in [3] which consist of tree like structure for achieving wideband isolation.

For the use of portable devices, a compact diversity antenna which operates in the UWB frequency range 3.1 to $5 \mathrm{GHz}$ is proposed in [4]. WCDMA (1.92 -2.17 GHz), WiMAX (2.3$2.5 \mathrm{GHz})$, WLAN (2.4 GHz), and UWB (3.1-10.6 GHz) bands are covered by MIMO antenna in [5]. A vector antenna consists of loop antenna and two orthogonal bowtie antennas which operate in the 3.6-8.5 GHz band [6].

In annular slot antenna, two microstrip lines feed the antenna simultaneously to obtain pattern diversity [7]. Effects of feeding cable on measurement and sizes of small ground plane on planar UWB monopole antenna is studied [8]. By using single or multiple antennas a spherical outdoor to indoor model is proposed to observe polarization [9]. In [10] a compact MIMIO antenna consisting of planar monopole antenna elements are presented to get frequency range more than 3.1 to $10.6 \mathrm{GHz}$ for portable UWB applications. Two stubs are attached in ground for better isolation and increase bandwidth. This MIMO antenna has low mutual coupling of less than $-15 \mathrm{~dB}$.

In this paper we have extended the work given in [10] to enhance the diversity capability of a MIMO antenna. Two more planar monopole antenna elements are added along with two stubs in the ground. Total four stubs are included in the proposed geometry but these stubs are slightly modified from stubs given in [10] for proper matching and good isolation. Section 2 presents basic antenna structure. Parametric study is explored in Section 3. In Section 4, experimental validation of the geometry is presented. Finally, the work is concluded in Section 5 .

\section{ANTENNA DESIGN}

The proposed geometry (Figure 1) is designed and optimized on FR4 substrate epoxy with relative permittivity 4.4 with dielectric loss tangent of 0.02 . The substrate size used for geometry design is of WxL1 $=52 \times 40 \mathrm{~mm}^{2}$ with height of 0.8 $\mathrm{mm}$. Four planar monopole antenna elements (PM1, PM2, PM3, and PM4) are included and are fed by microstrip lines. Among these monopoles, PM1 is perpendicular to PM2, and PM3 is perpendicular to PM4 for better isolation between input ports. To enhance the impedance bandwidth, four stubs are provided in the ground. Stub 1 is parallel with PM1, stub 2 is parallel with PM2, stub 3 is parallel with PM3, and stub 4 is parallel with PM4. Small ground connectors Ws3 are placed between ground planes of PM1 and PM2 and also in between ground planes of PM3 and PM4 to form a common ground plane. A rectangular slot of length Lfs and width $\mathrm{Wfs}$ is placed under each feeding in the ground to increase isolation and impedance matching at high frequencies. The simulation is carried out using high frequency structure (HFSS) 13 [11] to optimize the antenna in terms of input characteristics, radiation patterns, and antenna gain. 


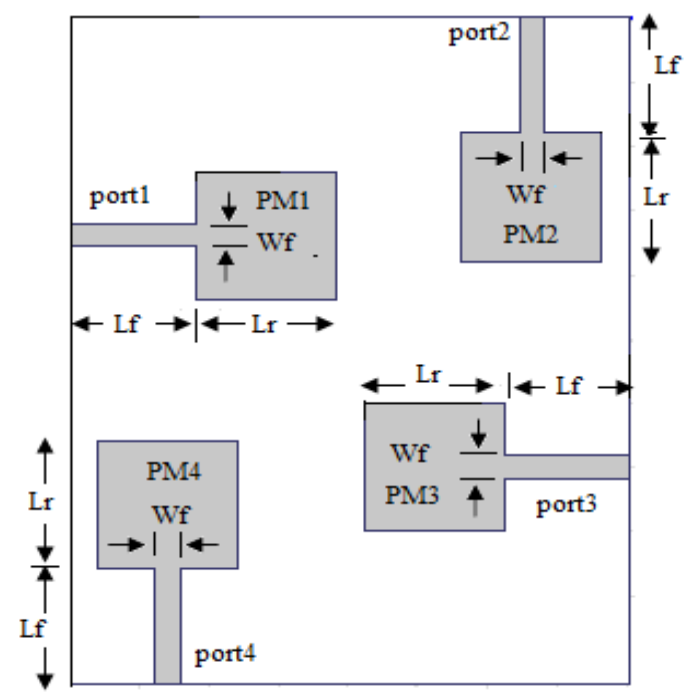

(a) Top view

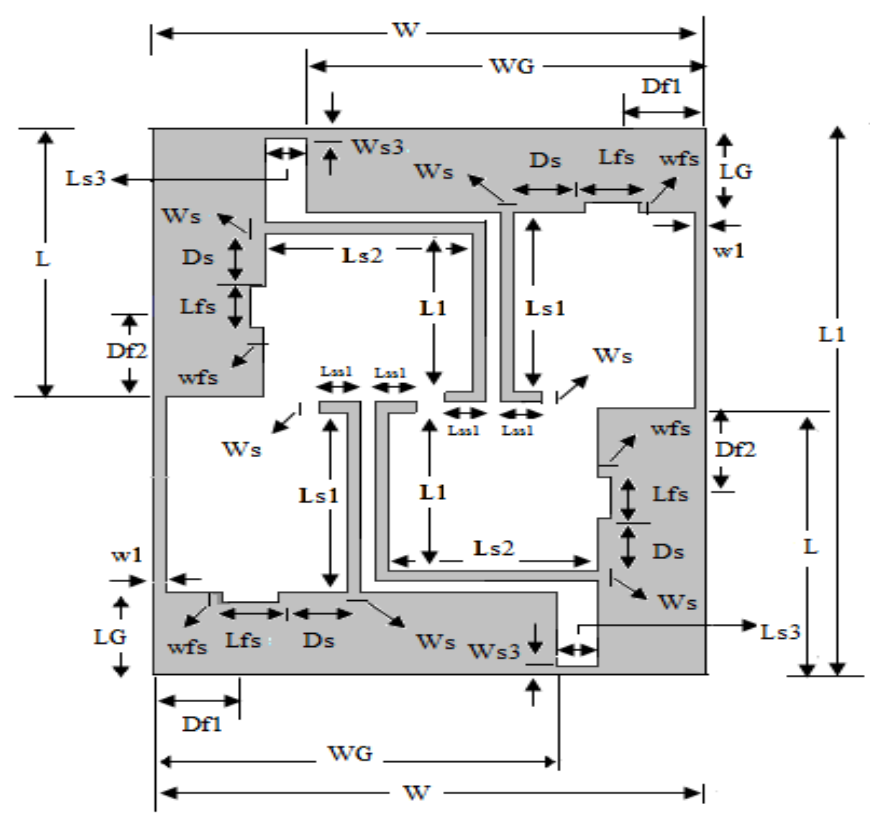

(b) Bottom view

Figure 1: Geometry of the proposed antenna

Table 1: Dimensions of the optimized geometry (mm)

\begin{tabular}{|l|l|l|l|l|l|l|}
\hline L & Lr & Lf & Ls1 & Ls2 & Ls3 & Lfs \\
\hline 26 & 10 & 9 & 17 & 16 & 3 & 4 \\
\hline Df1 & Ds & L1 & L2 & W & LG & Wf \\
\hline 6.1 & 5 & 52 & 15 & 40 & 8 & 1.8 \\
\hline Ws & Lss1 & Ws3 & Wfs & Df2 & WG & w1 \\
\hline 1 & 3 & 1 & 1 & 8.1 & 29 & 1 \\
\hline
\end{tabular}

\section{GEOMETRY OPTIMIZATION}

In this section parametric study is carried out for optimizing the proposed antenna geometry. Parameters chosen for optimization are width of short ground strip (Ws3), length of rectangular slot (Lfs), ground length (L). The detailed analysis of these parameters on antenna performance is carried out thoroughly and presented in the following subsections.

\subsection{Variation of Width of Small Ground Connectors}

In this study width of small ground connectors is varied in steps of $0.5 \mathrm{~mm}$ by keeping all other parameters constant. The simulated results of $S_{11}, S_{21}$ and, gain characteristics of antenna are shown in Figure 2 (a), (b) and (c) respectively. From the study of simulated results of $S_{11}, S_{21}$, and gain it is clear that for $\mathrm{Ws} 3=1 \mathrm{~mm}$ the results are optimum. 


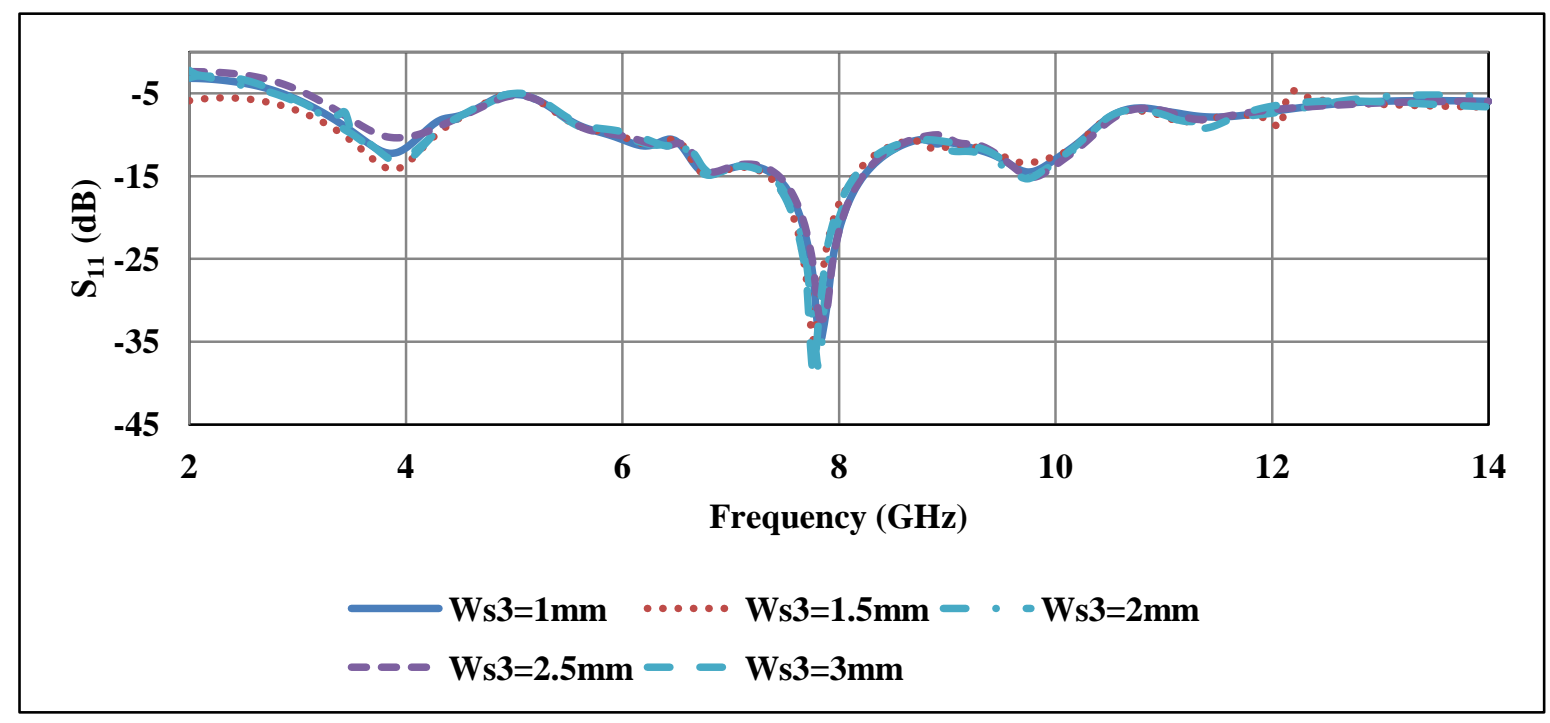

(a) Effect of width of short ground strip variation on $S_{11}$ characteristics.

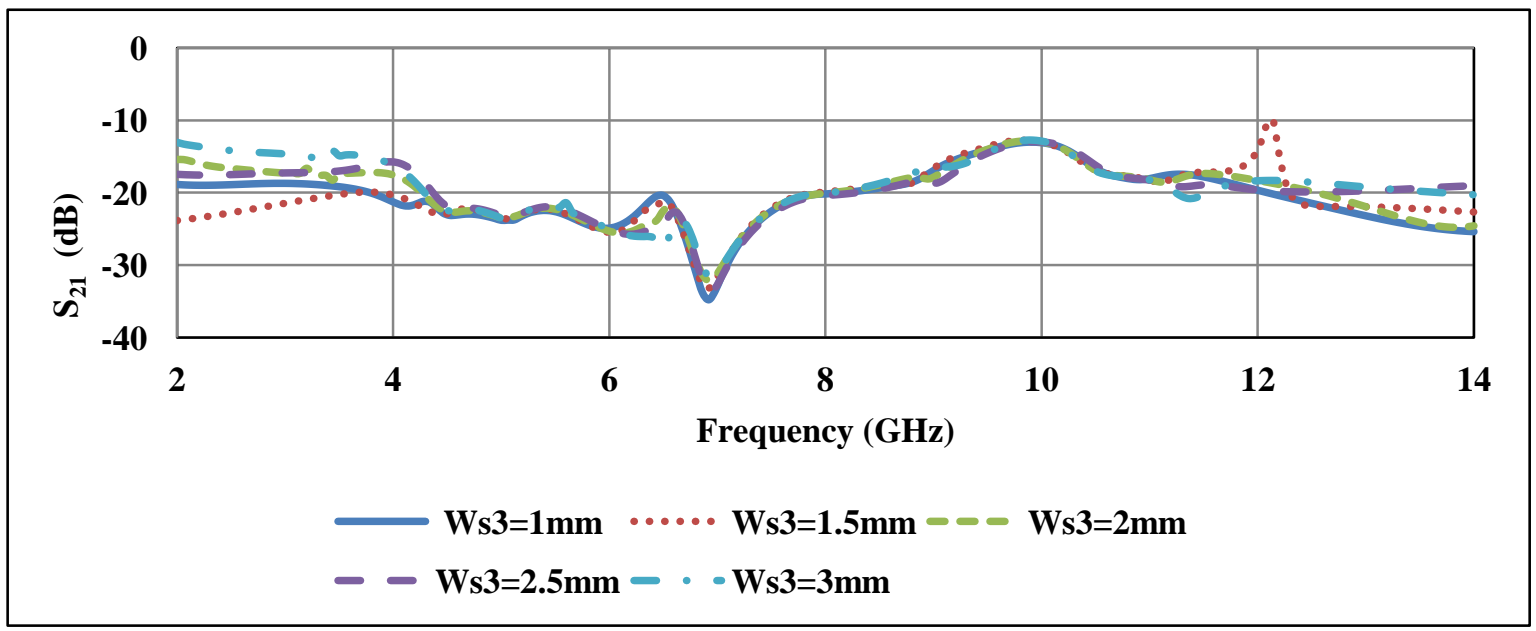

(b) Effect of width of short ground strip variation on $S_{21}$ characteristics.

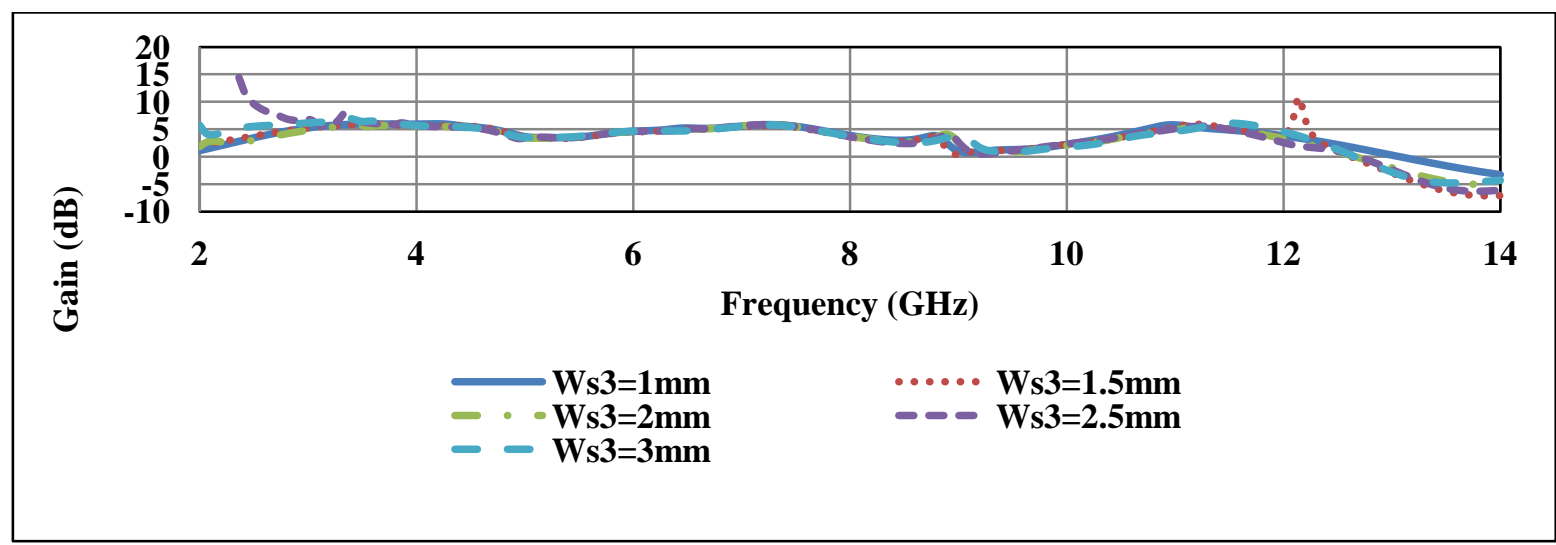

(c) Effect of width of short ground strip variation on gain characteristics.

Figure 2: $S_{11}, S_{21}$ and, gain vs. frequency characteristics.

\subsection{Variation of Length of Rectangular Slot}

In this parametric study rectangular slot length Lfs is varied from $3.8 \mathrm{~mm}$ to $4.2 \mathrm{~mm}$ by keeping all other parameters constant in the steps of $0.1 \mathrm{~mm}$. Effect of variation shows that the simulated results are optimum at $4 \mathrm{~mm}$. Results of this variation $S_{11}, S_{21}$ and, gain are shown in Figures 3 (a), (b), and (c) respectively. 


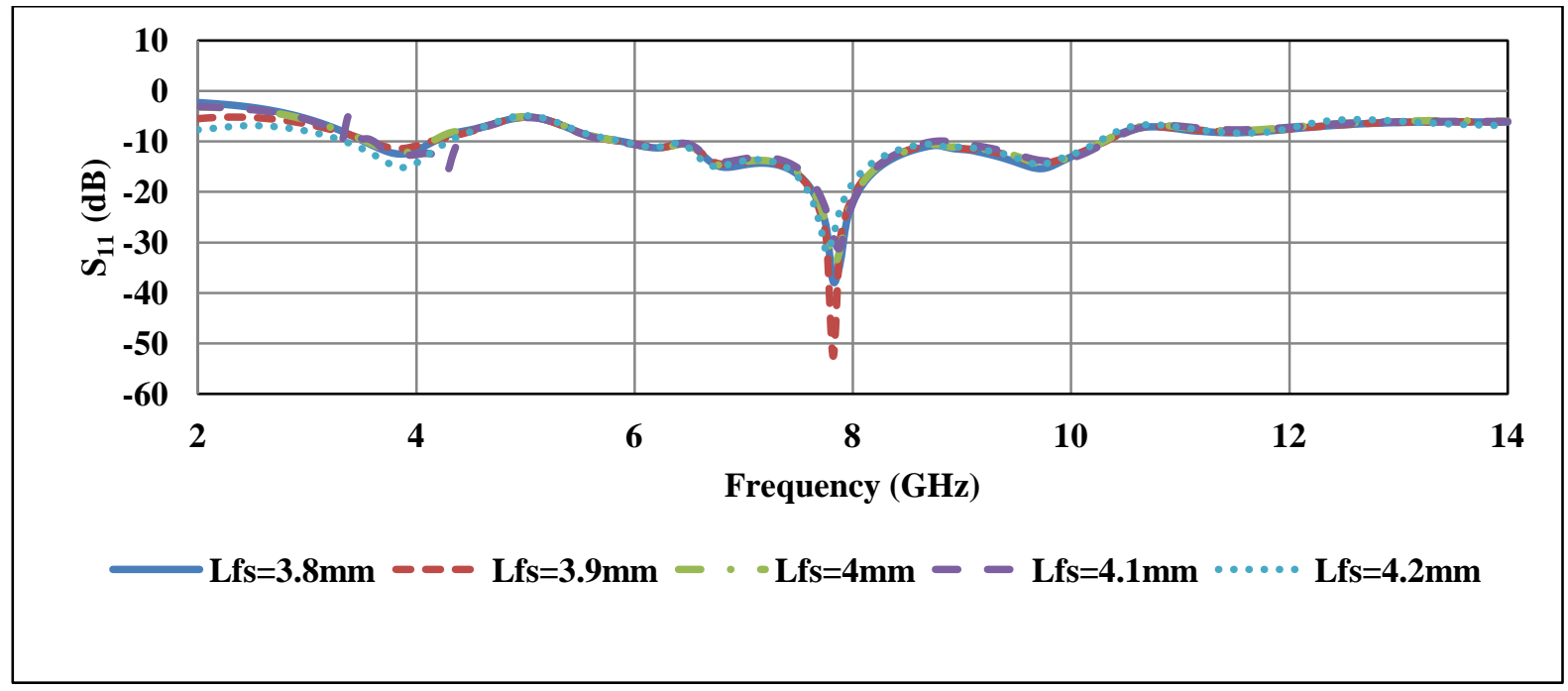

(a) Effect of length of rectangular slot variation on $S_{11}$ characteristics.

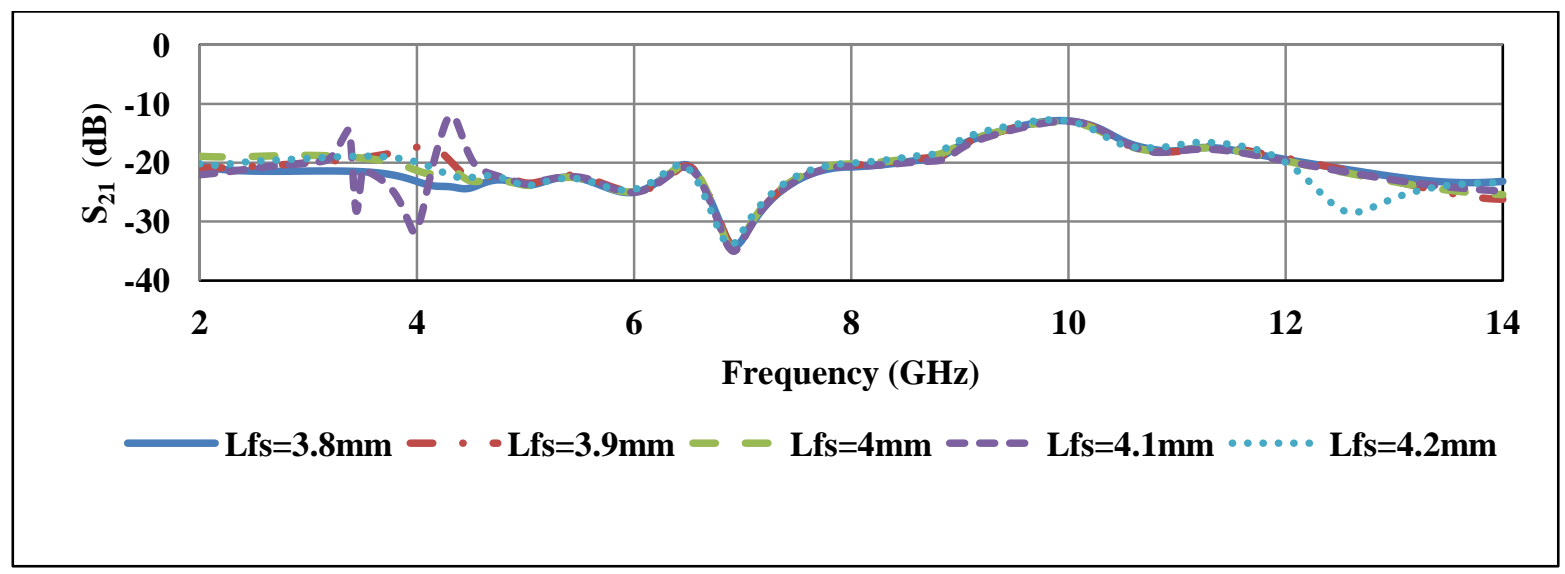

(b) Effect of length of rectangular slot variation on $S_{21}$ characteristics.

(c)

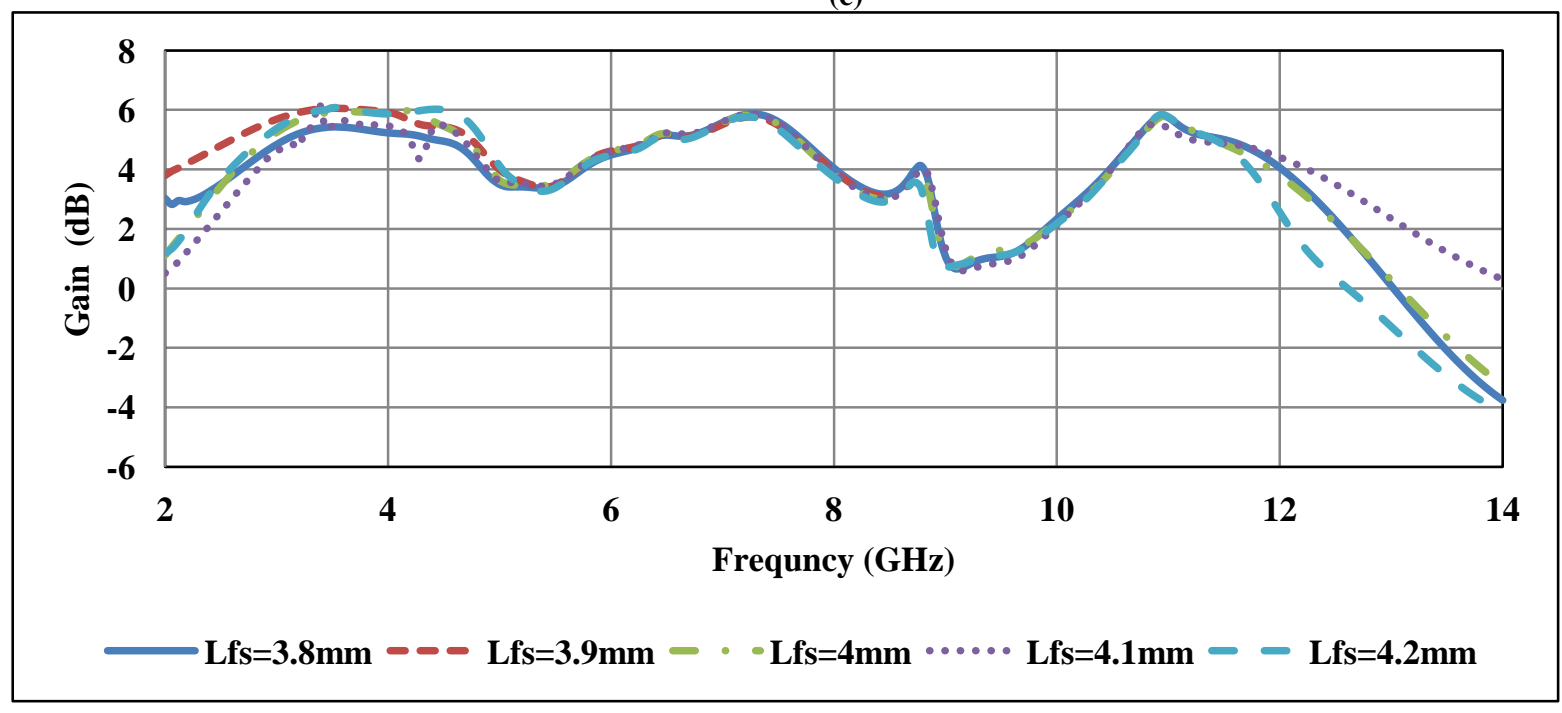

(c) Effect of length of rectangular slot variation on gain characteristics.

Figure 3: $S_{11}, S_{21}$ and, gain vs. frequency characteristics.

\subsection{Variation of Ground Length $(\mathrm{L})$}

Ground of PM1, PM2, PM3, and PM4 have same width LG

but different lengths WG and L. By keeping all other parameters constant, only $\mathrm{L}$ is varied in steps of $0.5 \mathrm{~mm}$ from $25 \mathrm{~mm}$ to $27 \mathrm{~mm}$. As a result of this the best characteristics 
are obtained at $\mathrm{L}=26 \mathrm{~mm}$. Effects of these variation on $\mathrm{S}_{11}$,

$\mathrm{S}_{21}$ and gain are shown in Figure 4 (a), (b) and (c) respectively.

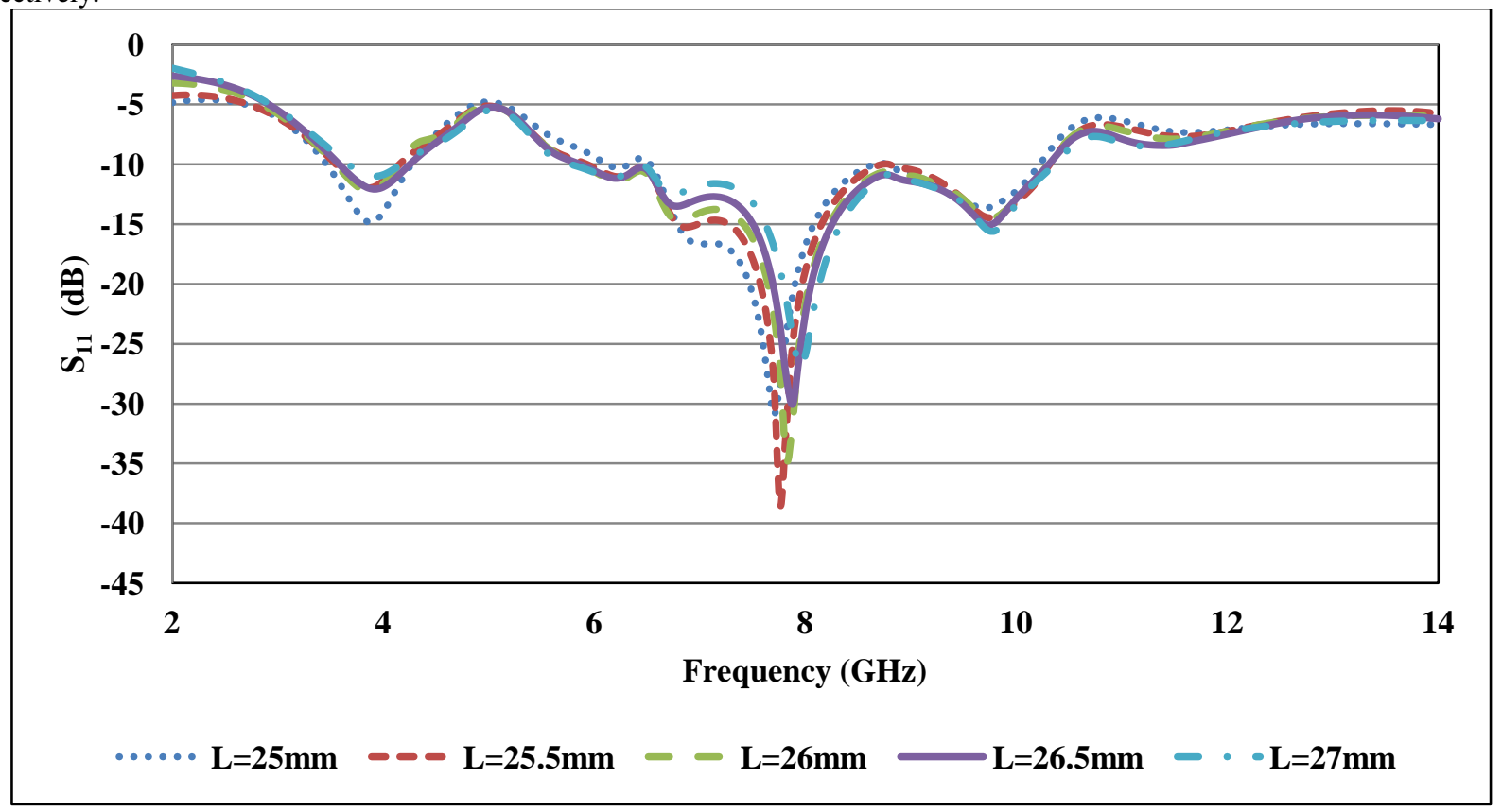

(a) Effect of ground length variation on $S_{11}$ characteristics.

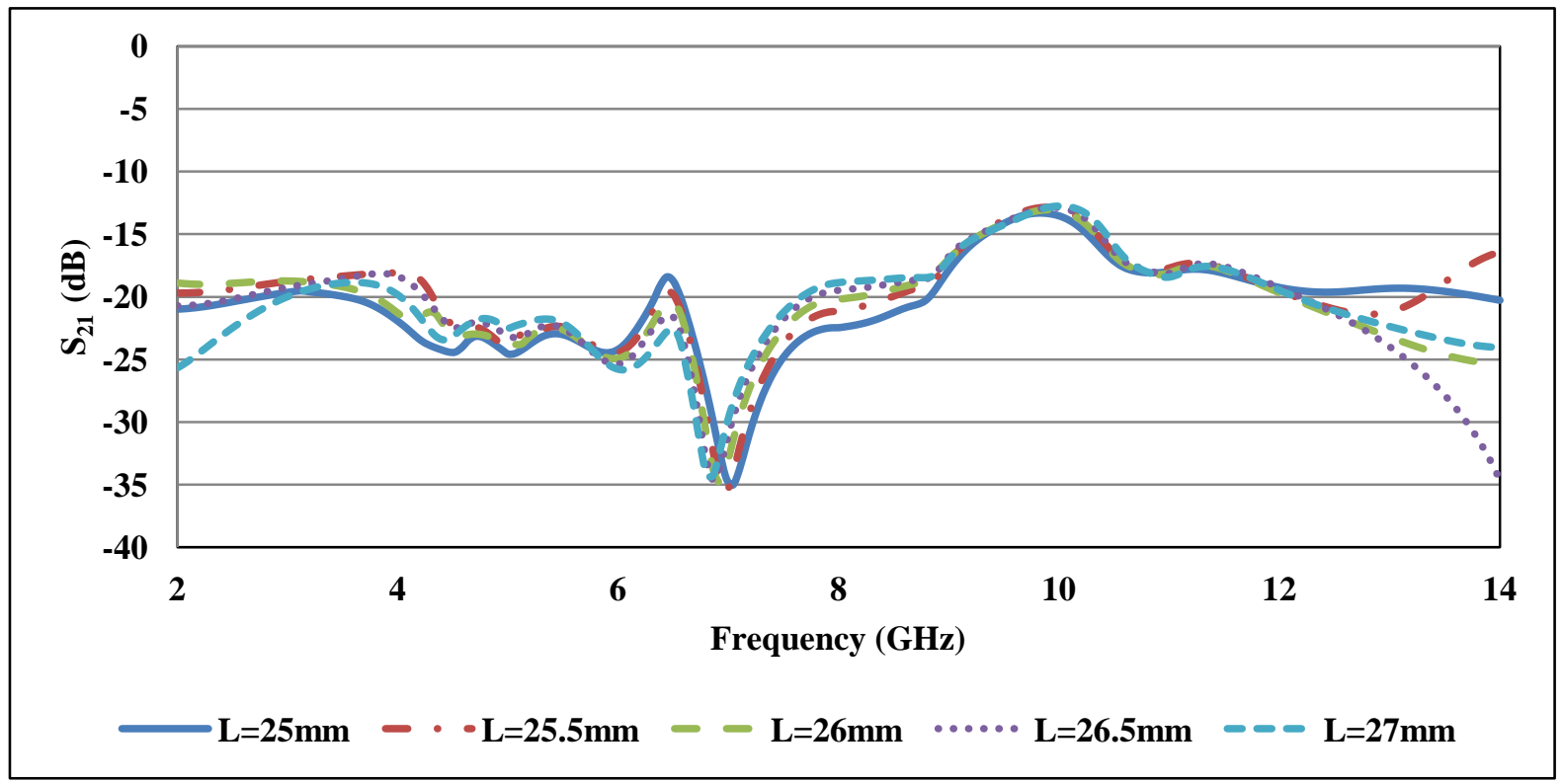

(b) Effect of ground length variation on $S_{21}$ characteristics. 


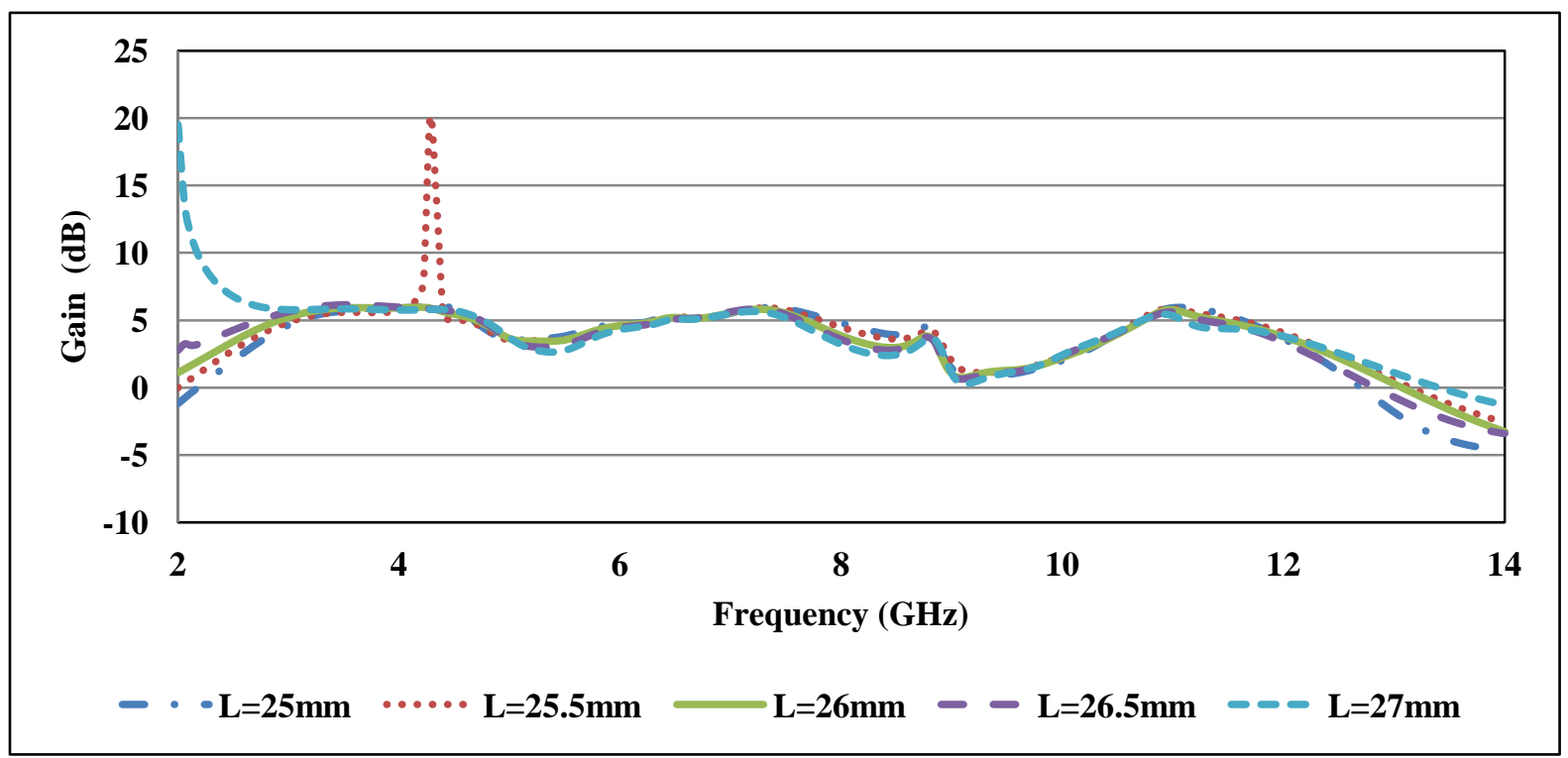

(c) Effect of ground length variation on gain characteristics.

Figure 4: $S_{11}, S_{21}$ and gain vs. frequency characteristics.

\section{EXPERIMENTAL VALIDATION OF THE GEOMETRY AND DISCUSSIONS}

The proposed geometry is shown in Figure 1 and optimized dimensions are given in Table 1. Geometry is fabricated on FR4 epoxy with relative permittivity 4.4 , dielectric loss tangent 0.02 and thickness $0.8 \mathrm{~mm}$. Photograph of fabricated prototype is shown in Figure 5. Figure 6 shows the photograph of measurement setup. Simulated and measured results are compared in Figure 7 and it can be observed that simulated results slightly mismatch with measured results. The slight mismatch may be attributed due to fabrication inaccuracies. Radiation patterns at different resonances are plotted and are presented in Figure 8.

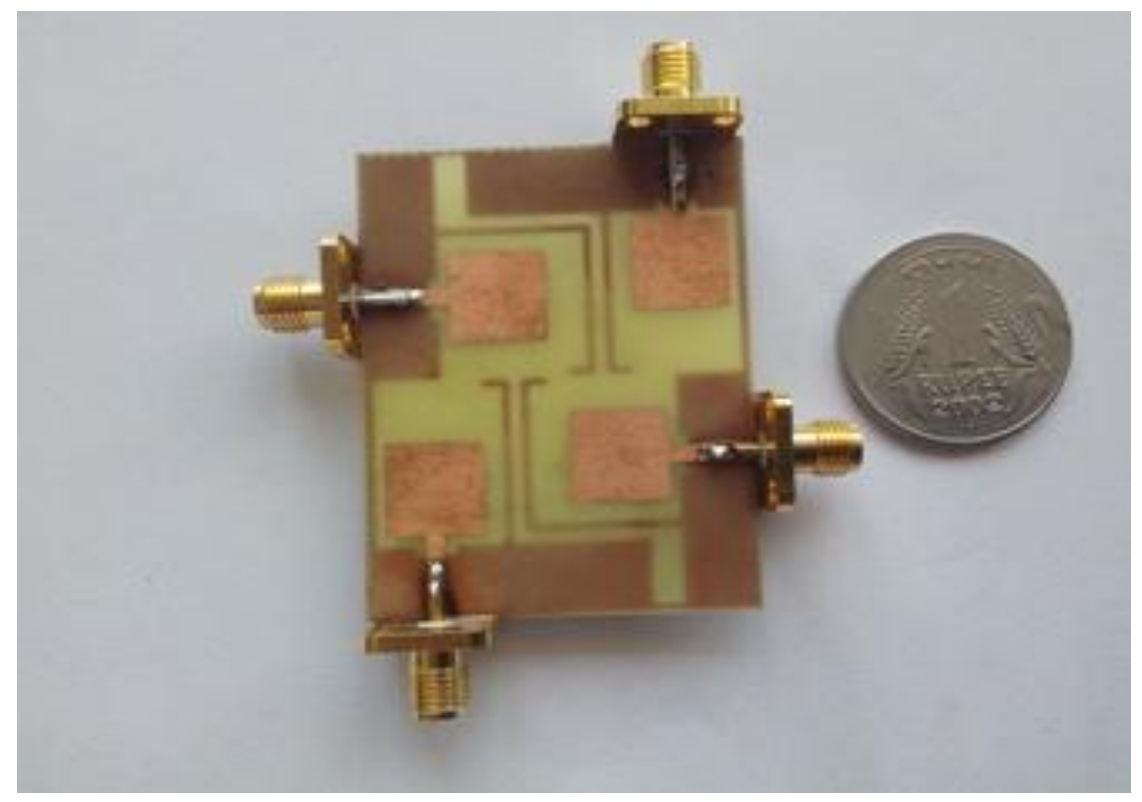

(a) 


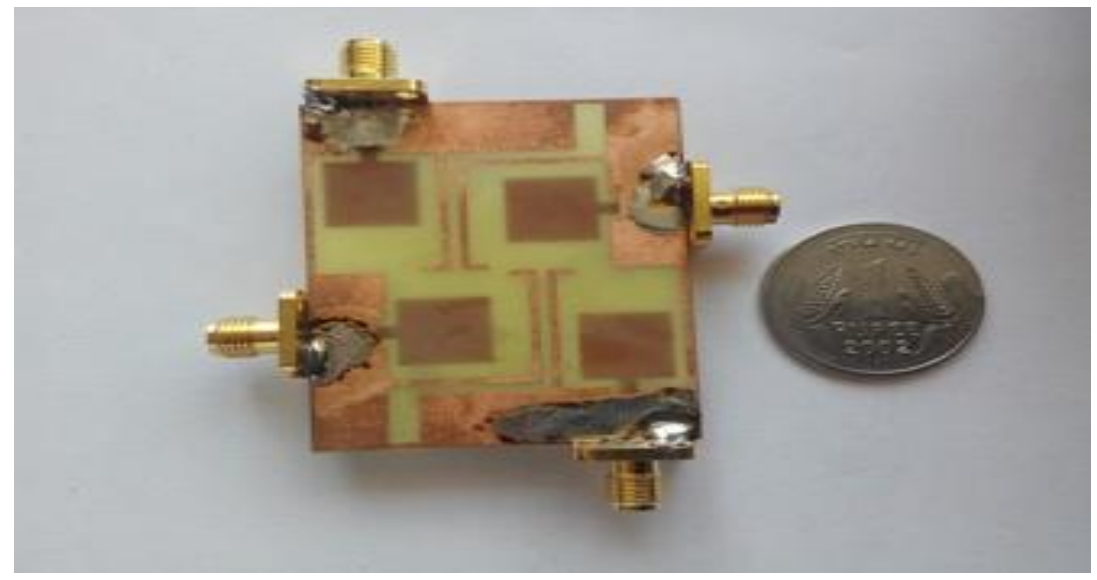

b)

Figure 5: Photograph of fabricated prototype (a) Front side (b) Back side.

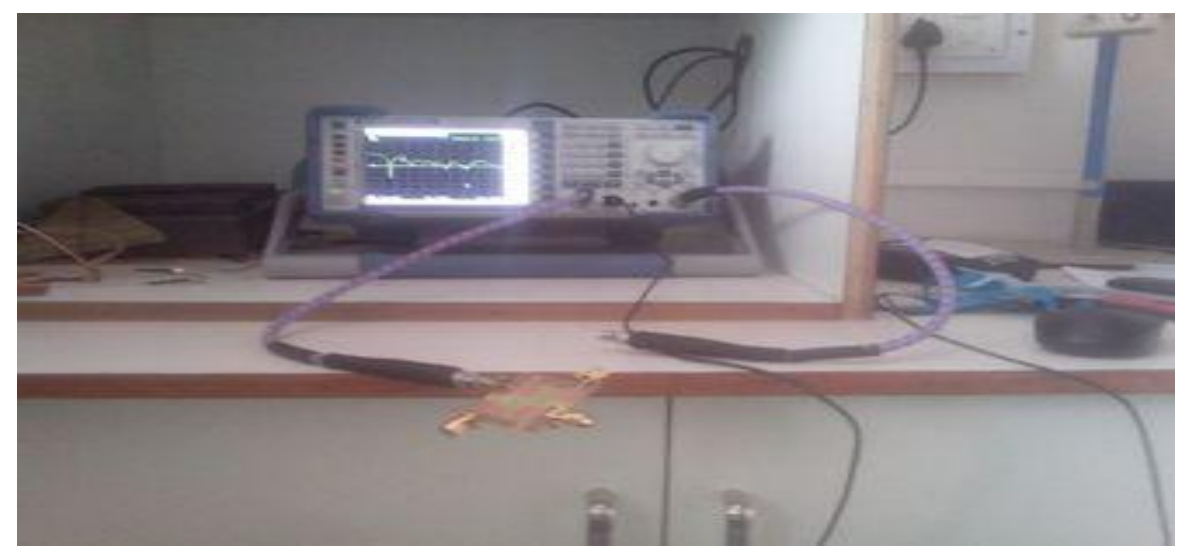

Figure 6: Photograph of measurement setup.

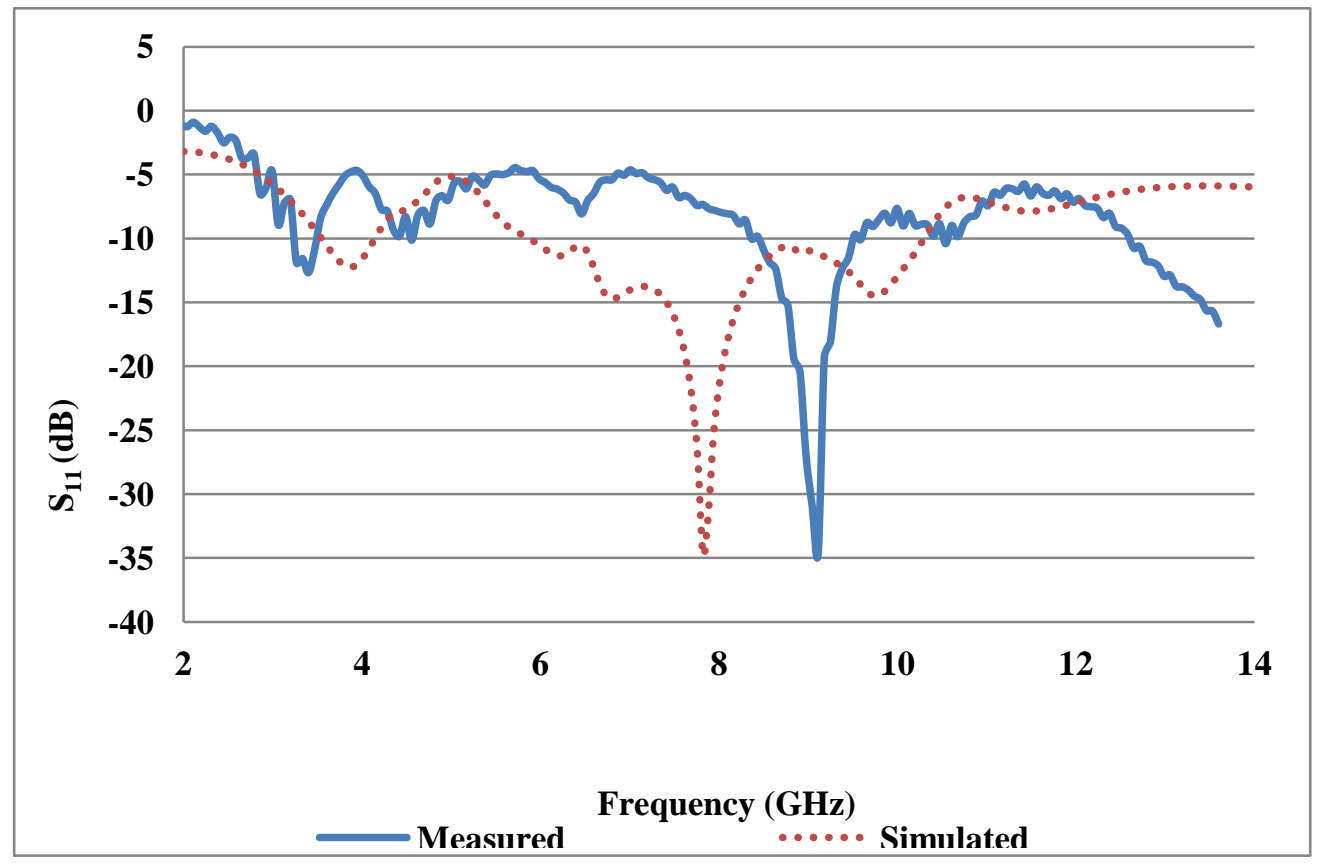

(a) Comparison of simulated and measured $S_{11}$ 


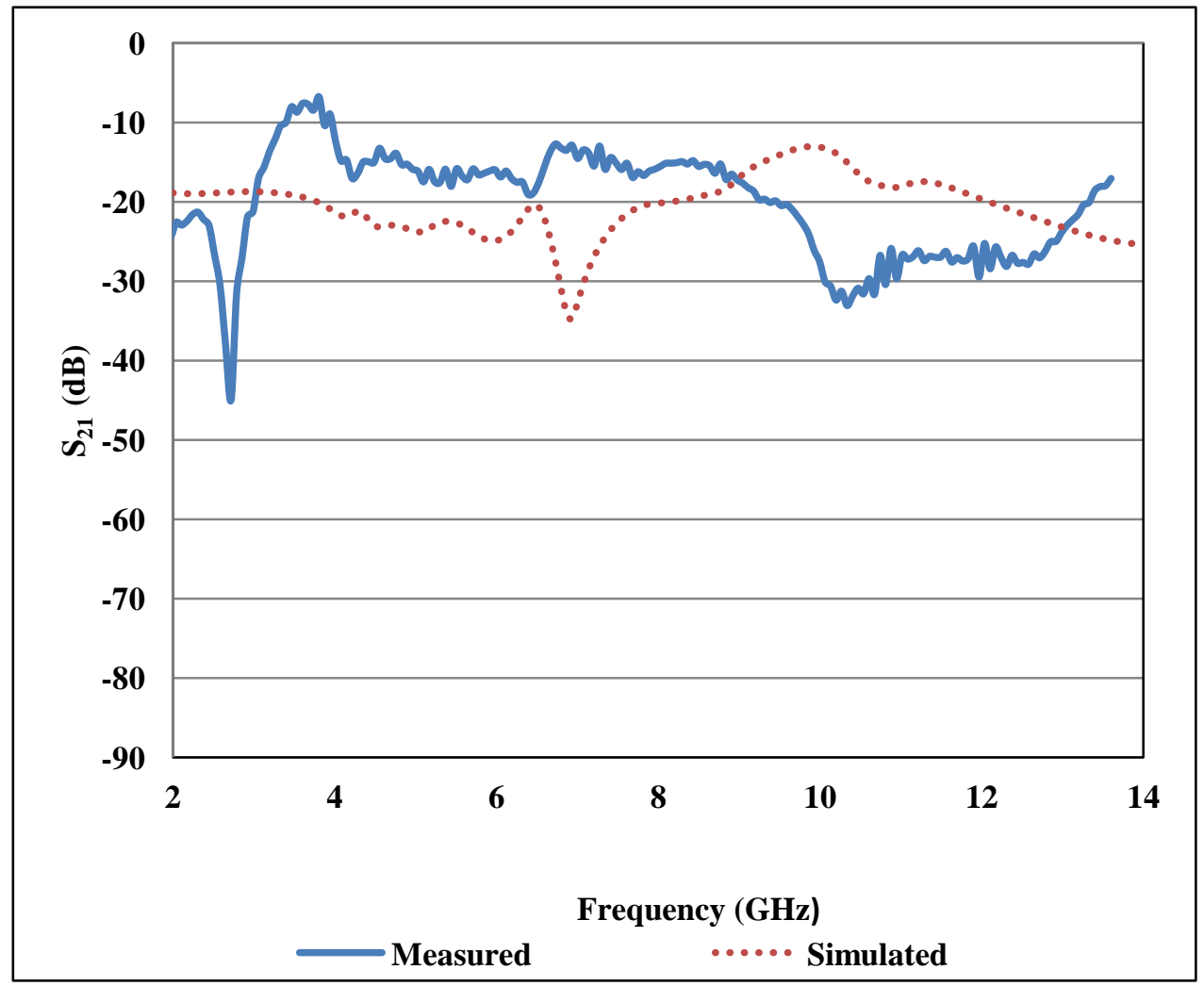

(b) Comparison of simulated and measured $S_{21}$

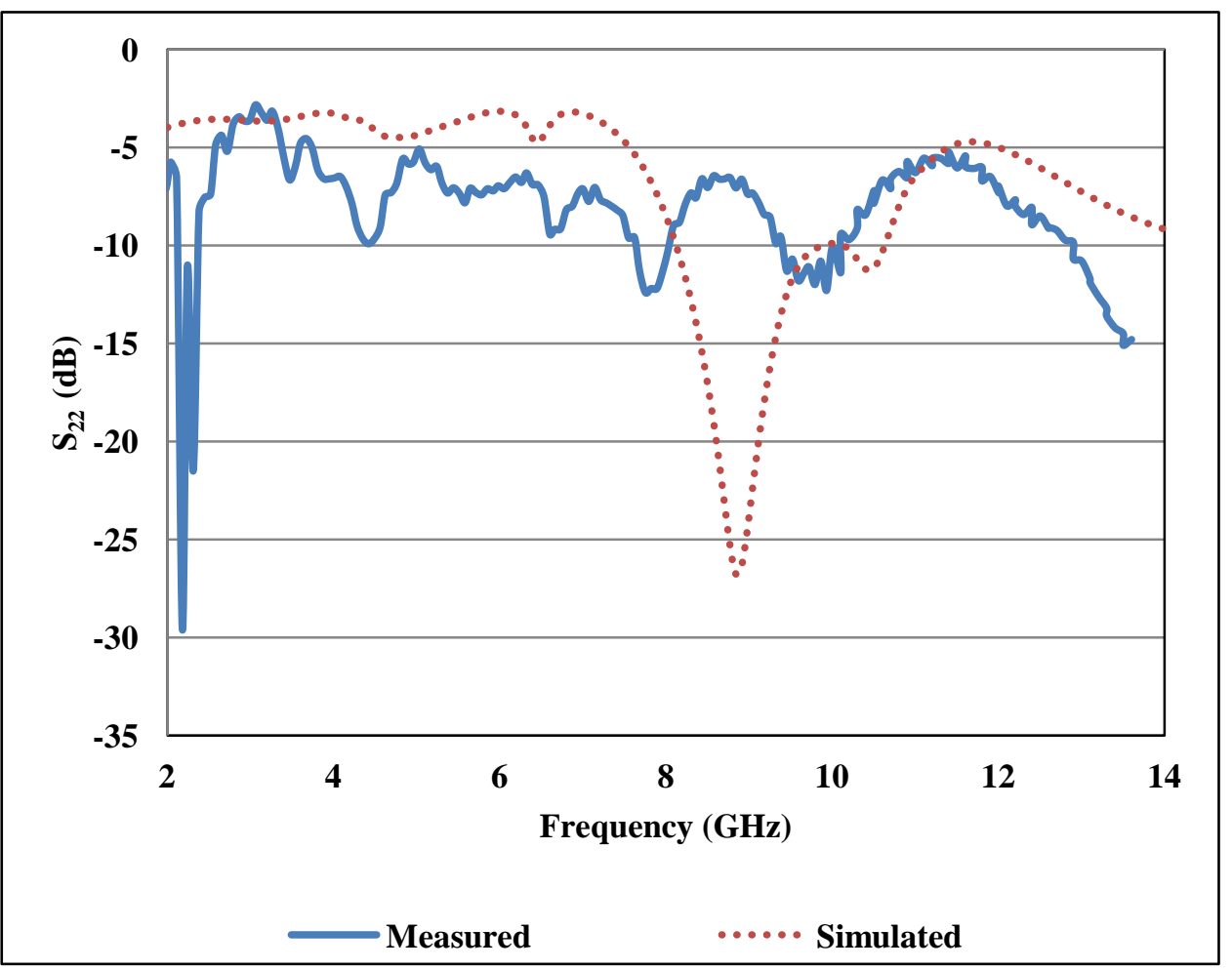

(c) Comparison of simulated and measured $S_{22}$

Figure 7: Simulated and Measured $S_{11}, S_{21}$, and $S_{22}$ vs. frequency characteristics. 


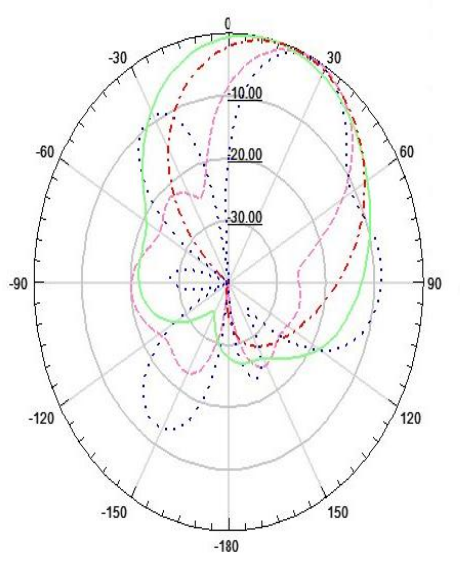

(a) $3.8 \mathrm{GHz}$

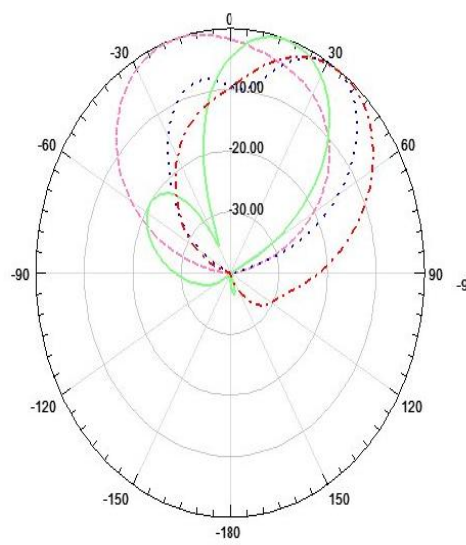

(b) $7.7 \mathrm{GHz}$

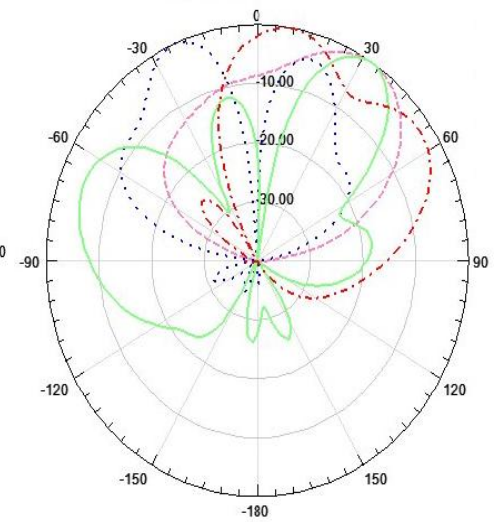

(c) $9.74 \mathrm{GHz}$

Figure 8: Radiation patterns at three resonances of the antenna (Solid line (Green) H-Co Plon.; Dash-dot (Red) H-Cross Plon.; Dotted line (blue) E-Co Plon.; Dashed line (Magenta) E-Cross Plon.).

\section{CONCLUSIONS}

UWB antenna with a size of $52 \times 40 \mathrm{~mm}^{2}$ is presented along with four stubs and four planar monopole antenna elements. Stubs are added in the ground to increase isolation as well as to increase gain and bandwidth. Two ground connectors are added to form a ground plane. A gain is positive till $13 \mathrm{GHz}$. The proposed antenna covers the FCC defined UWB band and hence, the geometry is a suitable candidate for those applications which use this band. The future work includes the measurement of gain, radiation patterns and mathematical analysis of the proposed antenna.

\section{REFERENCES}

[1] Federal Communications Commission (FCC), Revision of Part 15 of the Commission's Rules Regarding UltraWideband Transmission Systems First Rep. and Order, ET Docket 98-153, FCC 02-48, and Adopted: Feb. 2002; Released, Apr. 2002.

[2] L. Zheng and C. Tse, "Diversity and multiplexing: A fundamenta tradeoff in multiple-antenna channels," IEEE Trans. Inf. Theory, vol.49, pp. 1073-1096, May 2003.

[3] S. Zhang, Z. Ying, J. Xiong, and S. He, "Ultrawideband $\mathrm{MIMO}$ /diversity structure to enhance wideband isolation," antennas with a tree-like IEEE Antennas Wireless Propag. Lett., vol. 8, pp. 1279-1282, 2009.

[4] T. S. P. See and Z. N. Chen, "An ultrawideband diversity antenna," IEEE Trans. Antennas Propag., vol. 57, no. 6, pp. 1597-1605, 2009.
J.M. Lee, K. B. Kim, H. K. Ryu, and J.M.Woo, "A compact ultrawideband MIMO antenna with WLAN bandrejected operation for mobiledevices,"IEEEOAntennas Wireless Propag. Lett., vol. 11, pp. 990-993, 2012.

[5] A. Rajagopalan, G. Gupta, A. S. Konanur, B. Hughes, and G. Lazzi,"Increasing channel capacity of an ultrawideband MIMO system using vector antennas," IEEE Trans. Antennas Propag., vol. 55, no. 10, pp.2880$2887,2007$.

[6] M. Gallo, E. A. Daviu, M. F. Bataller, M. Bozzetti, J. M. Pardo, and L. J. Llacer, "A broadband pattern diversity annular slot antenna," IEEE Trans. Antennas Propag., vol. 60, no. 3, pp. 1596-1600, 2012.

[7] L. Liu, S. W. Cheung, Y. F. Weng, and T. I. Yuk, M. A. Matin, Ed.,"Cable effects on measuring small planar UWB monopole antennas," Ultra Wideband-Current Status and Future Trends, Oct. 2012.

[8] M. B. Knudsen and G. F. Pedersen, "Spherical outdoor to indoor power spectrum model at the mobile terminal," IEEE J. Sel. Areas Commun., vol. 20, no. 6, pp. 11561168, Aug. 2002.

[9] Li Liu, S. W. Cheung, and T. I. Yuk, "Compact MIMO antenna for portable devices in UWB applications," IEEE Transactions On Antennas And Propagation, vol. 61, NO. 8, pp. 4257-4264, 2013.

[10] HFSS 10.0 user's manual, Ansoft Corporation, Pittsburgh. 